\title{
Iran's Trend in Scientific Ranking in Health Policy Research Based on the Scopus Citation Database: A 15-Year Scientometric Study
}

\author{
Mahmood Salesi ${ }^{1}$, Ali Sadr ${ }^{2}$, Akbar Nikpajouh ${ }^{3}$, Amir Vahedian-Azimi ${ }^{4}$, Ehsan Mohammadi ${ }^{5}$, Ali Reza Karambakhsh ${ }^{6}$, \\ Parisa Shojaee ${ }^{3}$, Hamid Reza Pasha ${ }^{3 *}$ \\ ${ }^{1}$ Chemical Injuries Research Center, Systems Biology and Poisonings Institute, Baqiyatallah University of Medical Sciences, Tehran, \\ Iran \\ ${ }^{2}$ Yazd Cardiovascular Research Center, Shahid Sadoughi University of Medical Science, Yazd, Iran \\ ${ }^{3}$ Rajaie Cardiovascular Medical and Research Center, Iran University of Medical Sciences, Tehran, Iran \\ ${ }^{4}$ Trauma Research Center, Nursing Faculty, Baqiyatallah University of Medical Sciences, Tehran, Iran \\ ${ }^{5}$ Department of Bioelectric and Biomedical Engineering and Student Research Committee, School of Advanced Technologies in \\ Medicine, Isfahan University of Medical Sciences, Isfahan, Iran \\ ${ }^{6}$ Behavioral Sciences Research Center, Life Style Institute, Baqiyatallah University of Medical Sciences, Tehran, Iran
}

Corresponding Author: Hamid Reza Pasha, Rajaie Cardiovascular Medical and Research Center, Iran University of Medical Sciences, Tehran, Iran. Tel: +98-9124906120, Email: Pasha5587@yahoo.com

Received September 7, 2018; Accepted November 13, 2018; Online Published December 27, 2018

\begin{abstract}
Introduction: The current study evaluated Iran's ranking in health policy research compared with the world and with countries of West Asia and North Africa based on the Scopus database.

Methods: The present review considered 2 criteria for ranking: (1) the number of indexed papers, and (2) citations to the papers in Scopus. Changes in Iran's scientific ranking based on both indicators from 2002 to 2016 were compared with those of other countries.

Results: In general, Iran's ranking in the world had a relatively mild growth based on both indicators. Iran achieved its most desirable rankings in the based on number of papers in the year 2014 with the ranking of 19 and in the year 2011 with the ranking of 25 based on the number of citations. Iran ranked much higher based on the number of papers in West Asia and North Africa, going from 5th place in 2002 and 10th place in 2003 to first place in the region in 2014. Based on number of citations, Iran ranked second in the region in the year 2016.

Conclusions: In recent years, the status of research in the field of health policy in Iran has advanced. Efforts to index all Iranian health policy journals in the Scopus database and to increase scientific collaborations and financing can improve the position of Iran's scientific ranking in terms of number of articles and citations in the field of health policy.

Keywords: Health Policy, Research, Database

Citation: Salesi M, Sadr A, Nikpajouh A, et al. Iran's trend in scientific ranking in health policy research based on the Scopus citation database: a 15-year scientometric study. Int J Med Rev. 2018;5(4):159-162. doi:10.29252/IJMR-050406.
\end{abstract}

\section{Introduction}

The World Health Organization has focused on developing health policies and programs based on evidence-based research and, in this respect, has considered especially important the creation of more appropriate health information systems in policymaking. Due to its specific nature, policymaking in the health section has a significant status and a special sensitivity and specificity in comparison with other social sectors. ${ }^{1,2}$ Health policymaking is an interdisciplinary field that provides a comprehensive picture of how health systems adapt to health policies. Decision making in the health sector is often related to life and death subjects. In many cases, health is influenced by decisions that may not have a direct relation to healthcare, such as the effects of poverty on people's health, air pollution, economic policies related to smoking, nurses' stress, etc., but these decisions can affect people's health behavior. ${ }^{3-6}$ Given the complexity of health systems, policymakers and analysts must find a way to simplify the current situation. ${ }^{7,8}$ In writing health policy, 3 closely interrelated and sometimes interchangeable expressions are used: planning, management, and policy. It should be noted that governments, as service providers, have 2 significant roles that other providers do not: policymaking and regulation in line with people's personal responsibility for health. Policies are the basis for planning and are implemented while their establishment is managed. A policy that does not lead to an operational plan will not solve

Copyright $\odot 2018$ The Author(s). This is an open-access article distributed under the terms of the Creative Commons Attribution License (http:// creativecommons.org/licenses/by/4.0), which permits unrestricted use, distribution, and reproduction in any medium, provided the original work is properly cited. 
any problems in the country. ${ }^{9}$

Undoubtedly, the international status of each country depends on the conditions of knowledge production in that country. ${ }^{10}$ The scientific status of each country is determined through comparisons with other countries. This is also true with health policies. Given the fact that health policymaking in each country is proportionate to the needs and capabilities of that country, the research and knowledge production in the field of organization, policymaking, and other major issues in healthcare, education, and training systems can help policymakers make optimal decisions in this area.

Recognizing the research status quo in this field will help policymakers decide on and adopt sound health policies and determine the direction of research in this area. New studies require an understanding of the current status and a familiarity with the position of Iran among equally important countries in terms of scientific productions. To determine the scientific classification and differences between countries, the study and comparison of the scientific production in different countries are very important. Scientometric techniques, including numbers of articles and citations, are tools researchers use to assess the existing status and ranking of individuals, institutions, and countries. The international databases Scopus and Web of Science are the most important tools for sharing scientific findings and can be used as important sources for knowledge gathering. Accordingly, various studies have evaluated the status of scientific knowledge production in Iran in a variety of fields. Their results indicate that there has been a significant increase in the production of scientific knowledge in Iran, especially in the field of medicine. ${ }^{11-17}$ Because of the newly-established feature of health policymaking in Iran, however, no comprehensive research has been done on the current status of scientific productions in the field of health policymaking and Iran's position. Therefore, in line with the importance of directing researchers to this newly established field, the current study evaluated Iran's research rankings among health policymaking studies in the world and in West Asia and North Africa based on the Scopus citation database.

\section{Methods}

This review investigated Iran's position regarding health policy research in the world and in West Asia and North Africa. To extract Iran's ranking, 2 indices were considered in this study: (1) the number of articles indexed in the Scopus citation database, and (2) the number of citations for articles based on the Scopus citation database. Iran's ranking based on these 2 indices was extracted and its annual change trend was compared with that of other countries.

\section{Extracting the Scientific Ranking}

Information about Iran's ranking among different countries was extracted based on the number of articles and number of citations using (http://www.scimagojr.com/countryrank. php). This port is connected to Scopus and assesses and reveals the status of different countries in the world based on the latest Scopus reports. The calculations are available for different countries for the years 1996 to 2016, and the ranking system is based on various parameters, such as number of articles, number of citations, number of citations per article, the h-index, etc. In the current research, Iran's ranking was extracted based on the number of articles and number of citations. The category "medicine" and then the sub-category of "health policy" were selected along with "all regions" and "Middle East" for the 15-year interval 2002 to 2016. Iran's ranking in the general field of health policy in the world and in West Asia and North Africa was identified and extracted, and the results are reported in tables and graphs based on the number of articles and the number of citations.

\section{Results}

Iran's Ranking in the World

According to the SCImago database in 2016, a total of 220 journals related to health policy have been indexed in the Scopus database. The results of Iran's international ranking are shown in Table 1 and Figure 1. These results show the trend of change based on the number of articles and the number of citations.

\section{Iran's Ranking Based on Number of Articles}

In 2002, Iran ranked 48th in the world and fell to an even lower position in 2003. The country experienced relatively good growth in 2004 and 2005, and in the period from 2007 to 2016, the number of articles published was almost in sync with the slow tempo of publications in the world. The results showed that Iran achieved its most favorable ranking in the world in 2014 (19th place) (Table 1 and Figure 1).

\section{Iran's Ranking Based on Number of Citations}

Based on the number of citations, Iran ranked 67th in the world in 2002. From 2004 through 2015, Iran showed relatively modest growth and reached the rank of 27 th in the world in 2015. In 2016, however, the country fell ten spots to 37 th place. Iran achieved its highest ranking in the world

Table 1. Iran's Ranking in the Field of Health Policy Research in a 15-Year Interval Based on the Scopus Database

\begin{tabular}{|c|c|c|c|c|c|c|c|c|c|c|c|c|c|c|c|c|}
\hline & & \multicolumn{15}{|c|}{ Year } \\
\hline & & 2002 & 2003 & 2004 & 2005 & 2006 & 2007 & 2008 & 2009 & 2010 & 2011 & 2012 & 2013 & 2014 & 2015 & 2016 \\
\hline \multirow{2}{*}{ World } & Documents & 48 & 73 & 49 & 37 & 43 & 31 & 33 & 29 & 26 & 27 & 32 & 20 & 19 & 21 & 21 \\
\hline & Citations & 67 & 61 & 37 & 42 & 35 & 32 & 32 & 33 & 35 & 25 & 39 & 30 & 29 & 27 & 37 \\
\hline \multirow{2}{*}{ West Asia and North Africa } & Documents & 3 & 10 & 5 & 4 & 3 & 3 & 2 & 2 & 2 & 2 & 2 & 2 & 1 & 1 & 1 \\
\hline & Citations & 5 & 7 & 4 & 4 & 3 & 2 & 2 & 2 & 3 & 2 & 3 & 2 & 1 & 2 & 2 \\
\hline
\end{tabular}




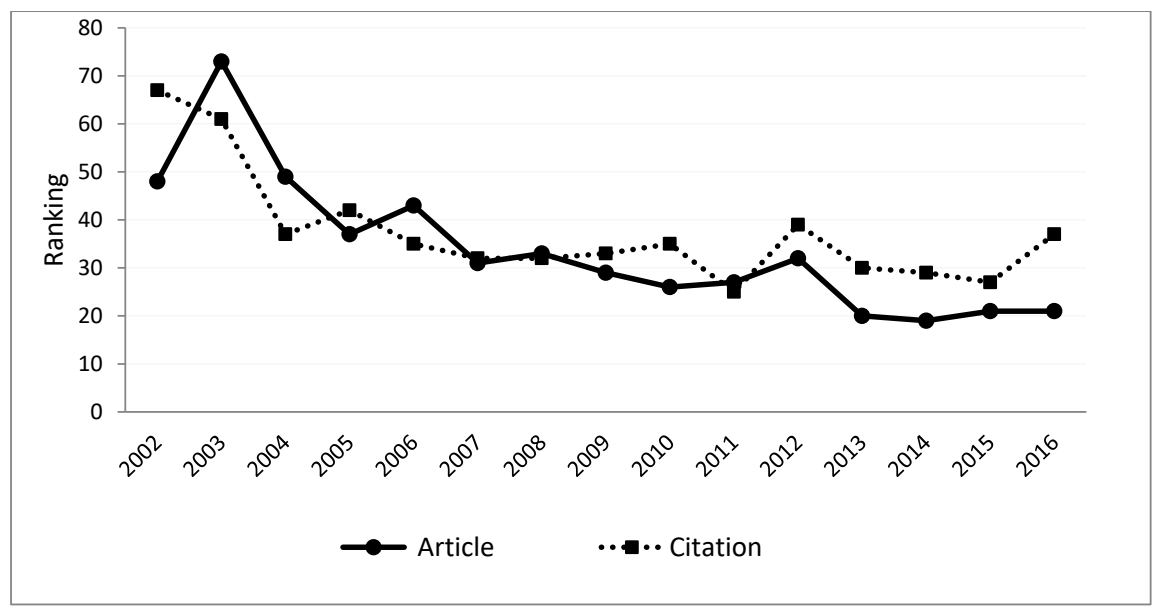

Figure 1. Iran's Worldwide Ranking in the Field of Health Policy Research Based on the Scopus Database.

based on number of citations in 2011 at 25th place (Table 1 and Figure 1).

Iran's Ranking in West Asia and North Africa

According to the SCImago database in 2016, a total of 3 journals related to health policy from West Asian and North African countries have been indexed in the Scopus database; they include almost one percent of the world's health policy journals. Of the 3 journals, 2 are Iranian journals related to the field of health policy.

\section{Iran's Ranking Based on Number of Articles}

In the year 2002, Iran ranked third in West Asia and North Africa based on number of articles. In 2003, however, it experienced a significant decrease, falling to tenth place in the region. Then, from 2004 to 2016, Iran climbed to first place (Table 1 and Figure 2).

\section{Iran's Ranking Based on Number of Citations}

According to the results of the current study, Iran ranked fifth in West Asia and North Africa based on number of citations in 2002. In 2003, with a negative growth rate, Iran fell to seventh place. From 2004 to 2014, Iran experienced very good growth and achieved first place in the region in 2014. In the years 2015 and 2016, however, Iran dropped to second place (Table 1 and Figure 2).

\section{Discussion}

The current study investigated the trend in change in the scientific position of Iran in the world and the region of West Asia and North Africa with emphasis on the field of health policy research. The results of this study indicated that Iran is in a propitious position for scientific research in the coming years. In 2016, Iran ranked 21st in the world based on number of articles and 37th in the world based on citation rates. In West Asia and North Africa, Iran ranked first and second based on number of articles and citation rates, respectively.

A literature review turned up no study on the research output in the field of health policy, but similar studies have been done on research conducted in various medical sciences fields. Iranian researchers have reported the state of science in Iran over the past 2 decades in the fields of general science and

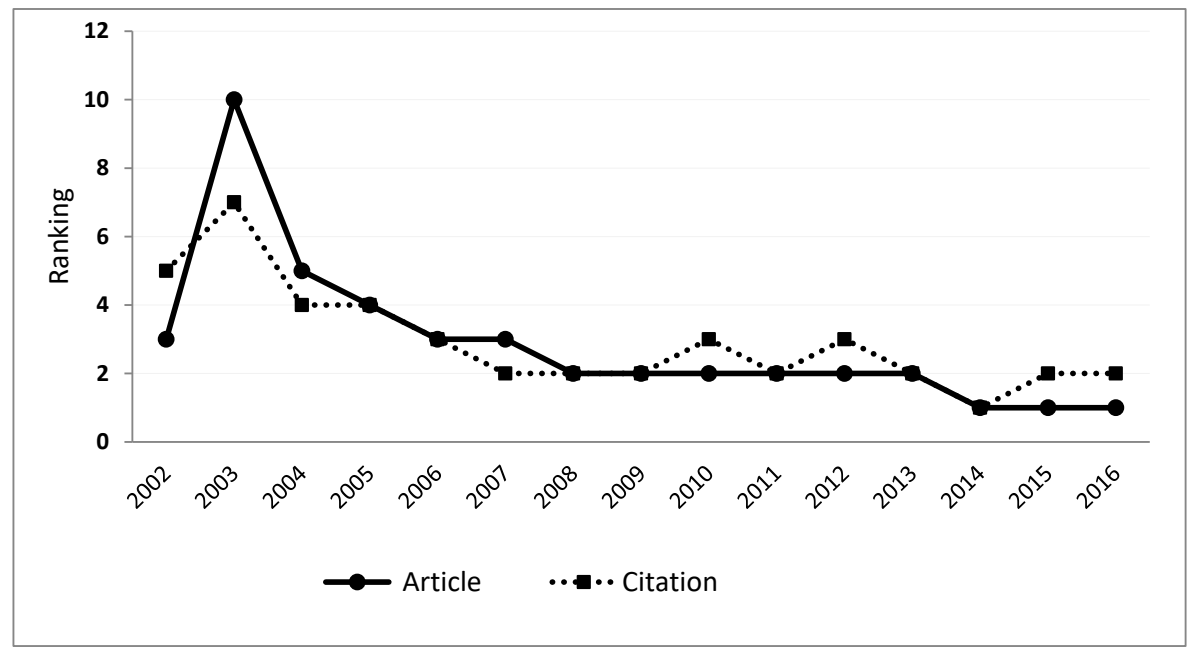

Figure 2. Iran's Ranking in West Asia and North Africa in the Field of Health Policy Research Based on the Scopus Database. 
medicine towards improvement. ${ }^{11-17}$ Some researchers have even ventured that the field of medical sciences plays a vital role in Iran's progress. ${ }^{18}$ In 2009, in its sixth annual report, the UK Research Center also reported its 2-fold growth of publications between 2006 and 2008. ${ }^{19}$ Some researchers consider the increased research budgets, the establishment of university-based research centers, and the graduation of Ph.D. and MSc students as the factors affecting the scientific position of Iran. ${ }^{16,17}$

The results of the present study showed that although Iran's ranking dropped suddenly in particular years, the general trend of Iran's scientific ranking has been relatively mild in both of the studied indices. It seems that in terms of both indices Iran's ranking needs to be improved, but this necessity is felt most strongly in the index of citations. The slow trend of research can affect the implementation of health policies. More attention needs to be given to research in this important area. The present study shows that by the end of 2016, from among the 3 journals indexed in the Scopus database related to the countries of Western Asia and North Africa, 2 journals, i.e. "The Journal of Research in Health Sciences" and "The International Journal of Health Policy and Management" are Iranian. It seems that the number of indexed journals from among those that can be assigned to this class in Scopus is not suitable, and any effort to index journals with related areas in Scopus can certainly improve Iran's ranking, at least in terms of the number of articles.

Another way to improve Iran's ranking is to pay particular attention to scientific collaborations in the production of research output. Various studies have shown that interpersonal, inter-university, and especially international collaborations increase the quality of scientific productions. Ultimately, these articles will be cited more often and will improve the position of the author and the country. ${ }^{20-22}$ Therefore, it seems that increased scientific collaborations along with funding to increase the quality of articles can improve Iran's scientific ranking.

\section{Conclusions}

In recent years, the status of research in the field of health policy has grown in Iran. Efforts to index all Iranian health policy journals in Scopus, increasing the number of scientific collaborations, and increasing financing for scientific research can improve Iran's scientific ranking in terms of number of articles and number of citations in the field of health policy.

\section{Authors' Contributions}

All authors developed the original idea, collaborated on data extraction, and wrote the manuscript.

\section{Conflict of Interest Disclosures}

The authors declare they have no conflicts of interest.

\section{References}

1. Ahmadi B, Farzadi F, Alimohammadian M. Women's health in Iran: issues and challenges. Payesh. 2012;11(1):127-137. [Persian].
2. Collins C, Green A, Hunter D. Health sector reform and the interpretation of policy context. Health Policy. 1999;47(1):69-83. doi:10.1016/S0168-8510(99)00003-2.

3. Buse K, Mays N, Walt G. Making health policy. McGraw-Hill Education; 2012.

4. Collins C, Hunter DJ, Green A. The market and health sector reform. J Manage Med.1994;8(2):42-55.doi:10.1108/02689239410059633.

5. Hashemian SMR, Farzanegan B, Fathi M, et al. Stress among Iranian nurses in critical wards. Iran Red Crescent Med J. 2015;17(6):e22612. doi:10.5812/ircmj.22612v2.

6. Vahedian-Azimi A, Hajiesmaeili M, Kangasniemi $M$, et al. Effects of Stress on Critical Care Nurses: A National CrossSectional Study. J Intensive Care Med. 2017:885066617696853. doi:10.1177/0885066617696853.

7. José Luiz C. de Araújo Jr, Maciel Filho R. Developing an operational framework for health policy analysis. Rev Bras Saude Mater Infant. 2001;1(3):203-221. doi:10.1590/S1519-38292001000300002.

8. Doshmangir L, Mostafavi H, Rashidian A. How to do Policy Analysis? A View on Approaches \& Modes of Policy Analysis in Health Sector. Hakim Health Sys Res. 2014;17(2):138-150.

9. Tarighat Monfared MH, Akhavan Bebahani A, Hasanzadeh A. Principles and basis of the national health policy. Tehran: The Office of Social Studies Majlis Research Centre (MRC) Publication; 2008. [Persian].

10. Uzoka F. A fuzzy-enhanced multiincleria decision analysis model for evaluating university academics' research output. Info Knowl Syst Manag. 2008;7:273-299

11. Osareh F, Wilson CS. A comparison of Iranian scientific publications in the Science Citation Index: 1985-1989 and 1990-1994. Scientometrics. 2000;48(3):427-442. doi:10.1023/a:1005648723433.

12. Sabouri AA. Research report status of Iran in 2002. Rahyaft. 2003;28:87-95. [Persian].

13. Osareh F, Marefat R. The growth of scientific productivity of Iranian researchers in Medline. Rahyaft. 2005;35:39-44. [Persian].

14. Radmard AR, Khademi H, Azarmina P, et al. Iran's biomedical sciences' research output in 2003: A bibliographic analysis of Medline and Excerpta Medica databases. Arch Iran Med. 2005;8(3):180-183.

15. Moin M, Mahmoudi M, Rezaei N. Scientific output of Iran at the threshold of the 21st century. Scientometrics. 2005;62(2):239-248. doi:10.1007/s11192-005-0017-5.

16. Habibi G, Rashidi A, Feldman MD. Emerging concerns about Iran's scientific and medical future. Lancet. 2006;368(9540):985. doi:10.1016/s0140-6736(06)69403-8.

17. Habibzadeh F, Vessal K. Scientific research in Iran: forgotten factors. Lancet. 2006;368(9546):1494. doi:10.1016/s01406736(06)69635-9.

18. Saadat SH, Izadi M, Aslani J, Ghanei M. How well establishment of research plans can improve scientific ranking of medical universities. Iran Red Crescent Med J. 2015;17(2):e18269. doi:10.5812/ircmj. 18269.

19. Six report on international comparative performance of UK research base 2009. http://www.bis.gov.uk/assets. Published 2012.

20. Persson O. Are highly cited papers more international? Scientometrics. 2010;83(2):397-401. doi:10.1007/s11192-0090007-0.

21. van den Besselaar P, Hemlin S, van der Weijden I. Collaboration and Competition in Research. High Educ Policy. 2012;25(3):263266. doi:10.1057/hep.2012.16.

22. Cronin B, Shaw D. Citation, funding acknowledgement and author nationality relationships in four information science journals. J Doc. 1999;55(4):402-408. doi:10.1108/EUM0000000007153. 